\title{
Factors associated with the performance of routine health information system in Yaoundé-Cameroon: a cross-sectional survey
}

Georges Nguefack-Tsague ${ }^{1,2^{*}}$ (D, Brian Bongwong Tamfon ${ }^{1,2}$, Ismael Ngnie-Teta ${ }^{3}$, Marie Nicole Ngoufack ${ }^{2,4,5}$, Basile Keugoung ${ }^{6}$, Serge Marcial Bataliack ${ }^{7}$ and Chanceline Bilounga Ndongo ${ }^{8}$

\begin{abstract}
Background: Routine Health Information Systems (RHIS) of low-income countries function below the globally expected standard, characterised by the production and use of poor-quality data, or the non-use of good quality data for informed decision making.This has negatively influenced the health service delivery and uptake. This study focuses on identifying the factors associated with the performance of RHIS of the health facilities (HF) in Yaoundé, so as to guide targeted RHIS strengthening.
\end{abstract}

Methods: A HF-based cross-sectional study in the 6 health districts (HDs) of Yaoundé was conducted. HFs were chosen using stratified sampling with probability proportional to size per HD. Data were collected, entered into Microsoft Excel 2013 and analysed with IBM- SPSS version 25. Consistency of the questionnaire was measured using Cronbach's alpha coefficient. Pearson's chi-square (and Fisher exact where relevant) tests were used to establish relationships between qualitative variables. Associations were further quantified using unadjusted Odd ratio (OR) for univariable analysis and adjusted odds ratio (aOR) for multivariable analysis with $95 \%$ confidence interval (Cl). A p-value of less than 0.05 was considered statistically significant.

Results: Of 111 selected HFs; 16 (14.4\%) were public and 95 (85.6\%) private. Respondents aged 24-60years with an average of $38.3 \pm 9.3$ years; 58 (52.3\%) males and 53(47.7\%) females. Cronbach's alpha was 0.96 (95\%Cl: 0.95-0.98, $p<0.001)$, proving that the questionnaire was reliable in measuring RHIS performances. At univariable level, the following factors were positively associated with good performances: supportive supervision $(\mathrm{OR}=3.03(1.1,8.3)$; $p=0.02)$, receiving feedback from hierarchy $(\mathrm{OR}=3.6(0.99,13.2) ; p=0.05)$, having received training on health information $(\mathrm{OR}=5.0(1.6,16.0) ; p=0.003)$, and presence of a performance evaluation plan (OR=3.3 $(1.4,8.2), p=0.007)$. At multivariable level, the only significantly associated factor was having received training on health information $(\mathrm{aOR}=3.3$ $(1.01,11.1), p=0.04)$.

Conclusion: Training of health staff in the RHIS favors RHIS good performance. Hence, emphasis should be laid on training and empowering staff, frequent and regular RHIS supervision, and frequent and regular feedback, for an efficient RHIS strengthening in Yaoundé.

Keywords: Routine health information system, Associated factors, Medical informatics, Medical informatics applications, Health informatics

\section{Background}

The health information system (HIS) makes up one of the pillars of the health system (HS) whose responsibility is the generation of data to facilitate the functioning of the 
other HS components: service delivery, health workforce, access to essential medicines, financing, and leadership [1]. A good HIS ensures the availability of good quality data and its use to support the informed decision-making process [2-4]. This highlights the importance of both the production of quality data and the use of the data for decision making at every level of the health pyramid. However, the RHIS of low-income countries experiences difficulties functioning at the globally expected standard, with respect to good data management and interpretation skills [5]. These systems are characterized by either the production and use of poor-quality data, or the non-use of good quality data by decision-makers, which negatively influence the delivery and uptake of health services [3-5]. Nevertheless, routine health information (RHI) availability permits a regular evaluation of the public health interventions both at the sub-national and national levels as well as an evaluation of HS strengthening interventions $[6,7]$ even though this has not been a regular practice in so many settings.

Since data generation is done at the level of the health facility, emphasis should be placed on the staff at this level through implicating them in the elaboration of RHI tools, planning, implementation, and evaluation of RHIS interventions. In Benin, exhaustibility of reporting increased from 16 to $89 \%$, and the proportion of reports with sufficient data quality increased from 18.8 to $45.8 \%$ after implicating staff in the conception and elaboration of data collection tools [8]. However, RHIS staff englobes a wider range of personnel, including clinical, administrative, support staff as well as other users from different sectors whose roles cannot be overlooked [9].

State-related factors that would affect the functioning of an RHIS include governance, planning, availability of material, financial and human resources, supportive supervision, information dissemination, and promotion of a culture of information use [10]. The identification and definition of indicators, elaboration of tools for data collection, preparing procedural guides, and the mastery of hardware and software tool for data processing and analysis constitute the technical factors [10]. Behavioural determinants like HIS users' demand, self-confidence, self-motivation, and competence to perform HIS tasks have also greatly influenced HIS performance and which require appropriate consideration and management accordingly [10-13]. Several African countries have sorted to harmonize and facilitate the HI collection through the putting into place of an open-source software platform. The most commonly solicited is the District Health Information System (DHIS) version 2, which has proven to improve the completeness of reporting [14].
The Cameroon health system is divided into 3 pyramidal levels. These include: the central (national), the intermediate (regional), and the peripheral (sub-regional) levels. Three sub-sections exist in the system: the public, private (private non-profit-making and private profitmaking), and the traditional sub-sections $[15,16]$. All these sub-sections are under the authority of the Ministry of Public Health. At each pyramidal level, there are administrative structures, health facilities, and also dialogue structures with linkage to the community [15]. The health facility is the point of entry of the clients (patient) $\mathrm{s}$ into contact with the health system and has as role to administer healthcare services to the clients.

The health sector is further segmented into 5 components ( 3 are vertical and 2 are horizontal). Vertical components are: health promotion, disease prevention, and disease management. Horizontal components include: health system strengthening, and governance [15]. Thus, services administered by the health facilities include those of the three vertical components of the health sector.

Following the standardization of data collection by the Cameroon Ministry of Public Health (MOPH) through the implementation of DHIS 2 [16], there is a tendency of improved HI management. This is due to the fact that both public and private HFs have as obligation to report through DHIS 2, thus improving on completeness and timeliness of reporting. Though not yet evaluated, this tool facilitates not just complete and timely reporting, but also facilitates feedback. Nevertheless, lack of management support, lack of skills by users, lack of computers, poor internet, and electricity coverage have been identified as potential challenges related to the efficient use of DHIS 2 [15].

Cameroon Health Sector Strategy (HSS) for the health information system (HIS) states: "By 2027, ensure the development of health research and the availability of quality health information system for evidence-based decision-making at all levels of the health pyramid" [16]. HSS aims at attaining $90 \%$ of health facilities having a well-organized system of data management [16]. To reduce the hindrances in meeting the HSS objectives and other health-related Sustainable Development Goals (SDGs) target for HIS, it is not only important to ensure the availability of RHI but also a performant RHIS that produces quality health information, as well as ensure its regular evaluation. Following Tamfon et al. [17] who determine the inadequate functionality of the RHIS of the HFs in Yaoundé, this study aims at identifying associated factors to good performance of the RHIS in Yaoundé; so as to guide targeted RHIS strengthening, and enable the re-orientation of the limited strengthening resources. 


\section{Methods}

\section{Study design and setting}

We carried out a facility-based cross-sectional study for a period of 5 months extending from 1st May 2019 to 30th September 2019 in the 6 health districts (HDs) in Yaoundé. These HDs include: Biyem-assi, Cité Verte, Djoungolo, Efoulan, Nkolbisson and Nkolndongo.

\section{Study variables}

The study variables were the socio-professional characteristics of participants, HF-related, and health system (HS)-related characteristics of participating HFs, and Health Facility and Community Information System Standards. Socio-professional characteristics included age, sex, professional qualification, years of experience, and function.

The independent variables were the HF-related, and health system (HS)-related characteristics: Status of the HF (public/private), Presence of health information unit ((HIU; (Yes/No)), Stable person in charge of statistics/ data management (Yes/No), Available functional computer for data management (Yes/No), Stable internet (Yes/No), Availability of call credit (Yes/No), RHIS supervision received (Yes/No), Receiving feedback from hierarchy (Yes/No), Receiving training on HI (Yes/No), and Presence of a performance evaluation plan (PEP, Yes/ No). A PEP is a written document that describes the process of carrying out the monitoring and evaluation of the RHIS performance, detailing the "What", the "How", and the "Why It Matters" for the RHIS evaluation, as well as exploiting evaluation results for RHIS performance improvement and decision making [18].

The dependent variable was the score of the Health Facility and Community Information System Standards. This variable was defined and classified into domains and subdomains by WHO and MEASURE Evaluation [19] as follows:

1 Management and Governance (Policies and Planning, Management, Human Resources)

2 Data and Decision Support Needs (Data Needs, Data Standards)

3 Data Collection and Processing (Data Collection and Management of Individual Client Data; Collection, Management and Reporting of Aggregated Facility Data; Data quality assurance; Information and Communication Technology (ICT))

4 Data Analysis, Dissemination, and Use (Analysis, Dissemination, Data Demand and Use)

The score of all the domains was calculated as follows [20]: i) Proportion of scores for the various subdomains: we summed the score for each item (question) in the subdomain, multiplied by 100 and divided by the maximum score for that subdomain.

ii) Proportion of scores for the domains: we summed up the obtained scores of the subdomains in the given domain, multiplied by 100 and divided by the maximum score for that domain.

iii) Global score for all the domains, we summed up all the obtained scores of all the domains, multiplied by 100 and divided by the maximum global score. The obtained global score was then grouped into good score (scoring 60\% and above) and poor score (less than 60\%).

\section{Sample size and sampling}

A minimum sample size (n) of $106 \mathrm{HF}$ that were visited was obtained using the formula: $n=\frac{Z^{2} \times P(1-P)}{d^{2}}$ [21], where $\mathrm{Z}$ is the quantile of the normal distribution at $5 \%$ level which equals to $1.96, \mathrm{P}$ is the proportion of adequately functioning HFs which is $10 \%$ [22], $\mathrm{d}$ is the precision $=0.06$ [21], and non-response rate of $10 \%$. HFs were selected through a stratified sampling that uses probability proportional to size in each HD. The two stratified variables were HD and HF status (Private, Public).

The recruitment criteria for HFs included functional public and private HFs of the operational level whose consent for participation was obtained. Respondents (one per HF) were either the head, person in charge of statistics/data management, or any other responsible staff, capable to provide the needed responses.

\section{Data collection}

Interviewers were recruited and trained to understand the objectives and the methodology of the study. Data were collected using the WHO/MEASURE Evaluation pre-established Rapid Assessment questionnaire [19] that was slightly modified to include the socio-professional characteristics of respondents, HF and HS-related characteristics. Each question was scored as: $O$ (no answer/ not applicable); 1 (not present, needs to be developed); 2 (needs a lot of strengthening); 3 (needs some strengthening); and 4 (already present, no action needed).

\section{Statistical data analysis}

Data were entered into Microsoft Excel 2013, cleaned and then exported for analyses using IBM-SPSS version 25 [23]. Frequencies and percentages (\%) were used to describe qualitative variables. Consistency of the RHIS assessment tool in measuring the gaps and weaknesses in the RHIS was measured using the Cronbach's alpha $(\alpha)$ whose score is comprised between 0 and 1 , and was 
interpreted as [24, 25]: (i) unacceptable if $\alpha<0.7$, (ii) acceptable if $0.7 \leq \alpha<0.8$, (iii) good if $0.8 \leq \alpha<0.9$, (vi) excellent if $\alpha \geq 0.9$. Pearson's Chi-square test (Fisher exact test where relevant) was used to establish relationships between qualitative variables. Associations were further quantified using unadjusted Odds ratio (OR) for univariable analysis and adjusted Odds ratio (aOR) for multiple logistic regression analysis with $95 \%$ confidence interval (CI). The Hosmer-Lemeshow (HL test)'s goodness of fit test was used to assess the adequacy of the multiple logistic regression. A $p$-value of less than 0.05 was considered statistically significant.

\section{Ethical considerations}

The study received ethical approval CE $\mathrm{N}^{0}$ 00786/ CRERSHC/2019 from the Regional Research Ethics Committee for Human Health of the Centre and the authorization $\mathrm{N}^{0}$ 00756-/AP/MINSANTE/SG/DRSPC/ CRERSH from the Regional Delegate of Public Health for the Centre Region. Study procedures were described to participants, during which they were briefly and clearly informed of their voluntary participation in the study; and that refusal to participate would have no negative consequences. Their informed consents were then obtained prior to the interview.

\section{Results}

Of 111 selected HFs (out of 799); 16 (14.4\%) were public and 95 (85.6\%) were private. Respondents aged $24-60$ years with an average of $38.3 \pm 9.3$ years; 58 (52.3\%) males and 53(47.7\%) females.

Distribution of health system-related characteristics As presented in Table 1, HIU, stable internet and PEP were available only in 27.9, 39.6 and $27.9 \%$ of HFs

\begin{tabular}{|c|c|c|}
\hline \multirow[t]{2}{*}{ Health system-related characteristics } & \multicolumn{2}{|c|}{ Proportions (\%) } \\
\hline & Yes & No \\
\hline PEP available & 27.9 & 72.1 \\
\hline Trained on $\mathrm{HI}$ & 63.1 & 36.9 \\
\hline Feedback received & 74.8 & 25.2 \\
\hline RHIS Supervision & 60.4 & 39.6 \\
\hline Call credit available & 62.2 & 37.8 \\
\hline Stable internet & 39.6 & 60.4 \\
\hline Functional Computer & 55.9 & 44.1 \\
\hline Stable data manager & 78.4 & 21.6 \\
\hline HIU present & 27.9 & 72.1 \\
\hline
\end{tabular}

PEP Performance Evaluation Plan, HI Health information, RHIS Routine health information system, HIU Health information unit respectively. The other characteristics: having received training on $H I$ (63.1\%), feedback received from hierarchy (74\%), RHIS supervision (60.4\%), and presence of functional computer (55.9\%) were present in more than $50 \%$ but less than $75 \%$ of the HFs. However, stable persons in charge of statistics/data management were available in $78.4 \%$ of HFs.

\section{Cronbach's analysis}

The consistency of the items of the RHIS tool was assessed using Cronbach's alpha. Overall Cronbach's alpha was 0.96 (95\%CI: $0.95-0.98, p<0.001)$, proving that the questionnaire was reliable in measuring RHIS performances. Table 2 shows Cronbach's alpha for various domains and subdomains; they vary for subdomains between 0.68 (Collection and Management of Individual Client Data) and 0.88 (Management); and for domains between 0.90 (Data Analysis, Dissemination, and Use) and 0.93 (Management and Governance).

\section{Factors associated with RHIS performance}

Table 3 shows that private non-profit-making HFs show a better performance (37.5\%) compared to public $(26.7 \%)$ and private profit-making $(25.0 \%)$ HFs $(p=0.52)$. HFs with a HIU performed slightly poorer (22.6\%) compared to HFs without a HIU (28.8\%), with

Table 2 Presentation of consistency of items using Cronbach's alpha

\begin{tabular}{|c|c|c|}
\hline & Domains and subdomains & $\begin{array}{l}\text { Cronbach's } \\
\text { alpha }(95 \% \\
\text { Cl) } * *\end{array}$ \\
\hline 1 & Management and Governance & $0.93(0.89-0.95)$ \\
\hline 1.1 & Policies and Planning & $0.87(0.81-0.92)$ \\
\hline 1.2 & Management & $0.88(0.85-0.91)$ \\
\hline 1.3 & Human Resources & $0.83(0.78-0.88)$ \\
\hline 2 & Data and Decision Support Needs & $0.91(0.88-0.93)$ \\
\hline 2.1 & Data Needs & $0.88(0.84-0.91)$ \\
\hline 2.2 & Standards and System Design & $0.83(0.77-0.87)$ \\
\hline 3 & Data Collection and Processing & $0.91(0.87-0.93)$ \\
\hline 3.1 & $\begin{array}{l}\text { Collection and Management of Individual Client } \\
\text { Data }\end{array}$ & $0.68(0.58-0.77)$ \\
\hline 3.2 & $\begin{array}{l}\text { Collection, Management, and Reporting of } \\
\text { Aggregated Facility Data }\end{array}$ & $0.81(0.74-0.86)$ \\
\hline 3.3 & Data Quality Assurance & $0.87(0.83-0.90)$ \\
\hline 3.4 & $\begin{array}{l}\text { Information and Communication Technology } \\
\text { (ICT) }\end{array}$ & $0.71(0.62-0.79)$ \\
\hline 4 & Data Analysis, Dissemination, and Use & $0.90(0.87-0.93)$ \\
\hline 4.1 & Data Analysis & $0.82(0.76-0.87)$ \\
\hline 4.2 & Information Dissemination & $0.79(0.72-0.84)$ \\
\hline 4.3 & Data Demand and Use & $0.76(0.68-0.82)$ \\
\hline
\end{tabular}

**All $p$-values were less than 0.001 
Table 3 Associated factors to the RHIS performance after univariable and multivariable analysis

\begin{tabular}{|c|c|c|c|c|c|c|c|}
\hline \multirow[t]{2}{*}{ Variables } & \multirow[t]{2}{*}{ Good } & \multirow[t]{2}{*}{ Poor } & \multirow[t]{2}{*}{ Total } & \multicolumn{2}{|l|}{ Univariable } & \multicolumn{2}{|l|}{ Multivariable } \\
\hline & & & & OR $(95 \% \mathrm{Cl})$ & $\mathbf{P}$ & aOR $(95 \% \mathrm{Cl})$ & $\mathbf{P}$ \\
\hline \multicolumn{8}{|l|}{ Status } \\
\hline Public & $4(26.7)$ & $11(73.3)$ & $15(100.0)$ & 1 & & & \\
\hline Private NPM & $6(37.5)$ & $10(62.5)$ & $16(100.0)$ & $0.6(0.1,2.8)$ & 0.52 & & \\
\hline Private PM & $19(25.0)$ & $57(75.0)$ & $76(100.0)$ & $1.09(0.3,3.8)$ & 0.89 & & \\
\hline \multicolumn{8}{|l|}{ HIU present } \\
\hline Yes & $7(22.6)$ & $24(77.4)$ & $31(100)$ & $0.7(0.3,1.9)$ & 0.50 & & \\
\hline No & $22(28.8)$ & $54(71.2)$ & $76(100)$ & 1 & & & \\
\hline \multicolumn{8}{|c|}{ Stable person in charge of statistics } \\
\hline Yes & $23(27.7)$ & $60(72.3)$ & $83(100)$ & $1.4(0.46,4.2)$ & 0.56 & & \\
\hline No & $5(21.7)$ & $18(78.3)$ & $23(100)$ & 1 & & & \\
\hline \multicolumn{8}{|c|}{ Functional computer } \\
\hline Yes & $19(31.7)$ & $41(68.3)$ & $60(100)$ & $1.76(0.7,4.2)$ & 0.30 & & \\
\hline No & $10(21.3)$ & $37(78.7)$ & $47(100)$ & 1 & & & \\
\hline \multicolumn{8}{|l|}{ Stable Internet } \\
\hline Yes & $15(35.7)$ & $27(64.3)$ & $42(100)$ & $2.2(0.9,5.2)$ & 0.80 & & \\
\hline No & $13(20.3)$ & $51(79.7)$ & $64(100)$ & 1 & & & \\
\hline \multicolumn{8}{|l|}{ Call credit } \\
\hline Yes & $20(30.3)$ & $46(69.7)$ & $66(100)$ & $1.5(0.6,3.9)$ & 0.35 & & \\
\hline No & $9(22.0)$ & $32(78.0)$ & $41(100)$ & 1 & & & \\
\hline \multicolumn{8}{|c|}{ RHIS Supervision } \\
\hline Yes & $23(34.8)$ & $43(65.2)$ & $66(100)$ & $3.03(1.1,8.3)$ & 0.02 & $1.9(0.6,5.6)$ & 0.2 \\
\hline No & $6(15.0)$ & $34(85.0)$ & $40(100)$ & 1 & & 1 & \\
\hline \multicolumn{8}{|c|}{ Feedback received } \\
\hline Yes & $26(32.1)$ & $55(67.9)$ & $81(100)$ & $3.6(0.99,13.2)$ & 0.05 & $2.0(0.5,8.0)$ & 0.3 \\
\hline No & $3(11.5)$ & $23(88.5)$ & $26(100)$ & 1 & & 1 & \\
\hline \multicolumn{8}{|l|}{ Trained on HI } \\
\hline Yes & $25(36.8)$ & $43(63.2)$ & $68(100)$ & $5.0(1.6,16.0)$ & 0.003 & $3.3(1.01,11.1)$ & 0.04 \\
\hline No & $4(10.3)$ & 35 (89.7) & $39(100)$ & 1 & & 1 & \\
\hline \multicolumn{8}{|l|}{ PEP } \\
\hline Yes & $14(45.2)$ & $17(54.8)$ & $31(100)$ & $3.3(1.4,8.2)$ & 0.007 & $2.3(0.9,6.0)$ & 0.09 \\
\hline No & 15 (19.7) 11 & $61(80.3)$ & $76(100)$ & 1 & & 1 & \\
\hline
\end{tabular}

non-significant difference $(p=0.50)$. Facilities with stable persons in charge of statistics (27.7\%), functional computer $(31.7 \%)$, stable internet $(35.7 \%)$, and call credit (30.3\%) performed better compared to those that did not possess the resources or benefitted from activities $(p=0.56, p=0.30, p=0.80$, and $p=0.35$ respectively). Facilities that benefitted from RHIS supervision (34.8\%), received feedback from hierarchy (32.1\%), facilities trained on HI (36.8\%) and those with a PEP (45.2\%) also presented better and statistically significant performances with respect to HFs that did not. Thus, the following factors were positively associated with good performances after univariable analysis: RHIS supervision $(\mathrm{OR}=3.03(1.1,8.3) ; p=0.02)$, receiving feedback from hierarchy $(\mathrm{OR}=3.6(0.99,13.2)$; $p=0.05)$, having received training on health information $(\mathrm{OR}=5.0(1.6,16.0) ; p=0.003)$, and presence of a performance evaluation plan $(\mathrm{OR}=3.3(1.4,8.2)$, $p=0.007)$. At multivariable level, the only significantly associated factor was having received training on health information $(\mathrm{aOR}=3.3(1.01,11.1), p=0.04)$. The Hosmer-Lemeshow's goodness of fit test showed that the multiple logistic model adequately fitted the data (Chisquared test $=5.02, \mathrm{df}=5, p=0.4$ ).

\section{Discussion}

This study assessed the factors associated with the performance of the RHIS as a whole component of the health system. It was evidenced that HFs that have benefited from $\mathrm{HI}$ training were more likely to perform better 
than their counterparts. Training on HI enables staff to acquire skills in basic computer use, planning, data analysis and management, data use, and interpretation. This also includes training on DHIS 2 which is the software used by the Ministry of Public Health for health data management. In a cross-sectional descriptive study carried out in Kenya [14], 80.8\% of the participants agreed or strongly agreed that the use of DHIS 2 by already trained workers improved the performance of the staff. Similar findings were obtained in Northwest Ethiopia [26] and Western Ethiopia [27]. Taking into consideration the increased need to train staff and the limited financial resources for this process, Tamfon et al. [17] suggested less costly training approaches which include online courses and video-recorded sessions that can be used for self-training, and also training of the district officer and giving them the responsibility to train their staff on regular bases during HD coordination meetings.

Sixty percent of HFs reported having been supervised, even though most of these facilities (34.8\%) presented better performance compared to their counterparts. This calls to question the quality and frequency of the supervision visits. Supervision aims to empower and support staff in carrying out their daily tasks [28]. This should be done in a regular manner with a checklist that includes all the aspects of the system. It was noticed that supervision irregularities were responsible for the poor performance of HMIS in Ethiopia [28]. This phenomenon applied to sending feedback by the hierarchy on the quality of forwarded data and the findings post supervision visit. Our study found that nearly a quarter of HFs acknowledged having received feedback from the superiors. This finding is similar to that of a study in Kenya, where $72 \%$ of the respondents stated to have received feedback concerning their reports from the superiors at unscheduled [29]. Also, Cheburet and Odhiambo-Otieno [29] obtained a statistically significant association between the feedback of data and frequency of feedback $(p<0.001)$. We noticed that $32.1 \%$ of HFs who have received feedback from superiors presented a good performance compared to $11.5 \%$ among HFs that did not receive feedback. It however points out the importance of regular and frequent feedback mechanisms to enable immediate discussion and resolution of problems for RHIS strengthening [30].

Functional computers for data management was present in about half $(55.9 \%)$ of the health facilities. Of these facilities, $31.7 \%$ had a good performance against $21.3 \%$ among facilities without one. This finding was similar to that obtained by Shiferaw et al. [26] in Ethiopia where he evidenced that the presence of a computer in a health department was associated with good use of health information [26]. However, the availability of a functional computer was proven to be significantly associated with HI use. In this study by Asemahgn [24] in Western Amhara of Ethiopia, facilities that had a computer were more likely to use HI for decision making, compared to those that did not have a computer. This difference in the findings could be explained in part by the differences in the outcome variable under investigation and also by the differences in the tools used. As earlier stated, we explored the performance of the RHIS domains as a whole, meanwhile, Asemahgn focused only on HI use. Nevertheless, both findings stress the importance of having a computer for data management in the HFs and departments. Lack of computers, as well as other factors, were also some challenges in strengthening the district-based health reporting through DHIS 2 in Uganda [31].

The presence of a functional computer alone in an HF or department will not guarantee effective and efficient HI management. This is complemented by the services of a stable and computer literate person in charge of statistics. The difficulties experienced by most HFs are that persons in charge of data management are unstable, untrained in HI management and computer skills, or occupy other posts [28]. Apart from this problem, our study indicates that HFs with stable persons in charge of statistics were more likely to perform better than their counterparts.

DHIS 2 was implemented with the hope of meeting the health sector strategic objective of attaining $80 \%$ completeness in monthly activities reporting by 2027 [16]. With this platform, only an internet connection can permit reports forwarding. There is good coverage in Yaoundé, but HFs located in remote areas have poor internet coverage. Our findings show that HFs with stable internet were likely to perform better than their counterparts. However, the problem of HFs in Yaoundé is not poor coverage, but rather the availability of internet communication cost. Though limited in resources, HD officers have been provided telephones with communication credit for communication with HFs. This improved performance with respect to HFs reporting and feedback sending by hierarchy.

Some limitations of the study include the fact that it didn't focus enough on other behavioural determinants such as the knowledge, skills, attitudes, values, and motivation of the people who collect, analyse, and use health data. In addition, our cross-sectional study design prevented the findings from showing causal relationships.

\section{Conclusion}

This study revealed that training of health staff in the RHIS is a determinant of the good performance of the RHIS system in Yaoundé. In this light, emphasis should 
be laid on training and empowering staff. Likewise, frequent and regular RHIS supervision, and frequent and regular feedback should also be implemented for an efficient RHIS strengthening in Yaoundé. Health authorities should carry the greater responsibility in the strengthening process through the creation of an enabling environment. This involves advocating and providing sufficient resources, monitoring, and evaluation of the implementation of RHIS policies by both public and private HFs for better management of data for evidence-based decisions making. However, the findings of this study also pave the way for further research in the domain of RHIS. Postimplementation evaluation studies will be better indicated to measure the change in the performance of the RHIS after the implementing these interventions. Secondly, cost-effective studies will be indicated to measure the cost effectiveness of these interventions especially in a low-income country setting.

\begin{abstract}
Abbreviations
Cl: Confidence Interval; DHIS2: District Health Information System 2; HD: Health District; HF: Health Facility; HI: Health Information; HS: Health System; HIS: Health Information System; HIU: Health Information Unit; HMIS: Health Management Information System; HSS: Health Sector Strategy; ICT: Information Communication Technology; MOPH: Ministry of Public Health; OR: Odds Ratio; PEP: Performance Evaluation Plan; RHI: Routine Health Information; RHIS: Routine Health Information System; SDG: Sustainable Development Goals; WHO: World Health Organisation.
\end{abstract}

\section{Acknowledgements}

We wish to thank the following persons, whose efforts led to the successful realisation of this study: District medical officers of Biyem-assi (Dr. Albert Bilounga), Cité Verte (Dr. Ottou Tsala), Djoungolo (Dr. Angelique Bitjocka), Efoulan (Dr. Anne Christine Ndzana), Nkolbisson (Dr. Yvette Essola Mbele) and Nkolndongo (Dr. Paul Onambele) for their assistance in facilitating the realisation of this study.We also thank Mrs. Armel Vivien Ngane and Jean-Marie Tsachoung for their technical support; and all the medical personnel (doctors, nurses, persons in charge of statistics, administrators etc.) for their collaboration in providing for us the needed information, without which this study would not have been realised.

\section{Authors' contributions}

Conception: BBT, GNT, CBN, SMB. Data collection: BBT, CBN, MNN. Analysis and interpretation: BBT, GNT, SMB. Manuscript writing: BBT, GNT, INT, BK, MNN, SMB. Revision of the manuscript: All the authors. Approval for submission: All the authors.

\section{Funding}

The authors received no funding for this study.

\section{Availability of data and materials}

The datasets used and/or analyzed during the current study are available on reasonable request.

\section{Ethics approval and consent to participate}

The research was approved by the Regional Research Ethics Committee for Human Health of the Centre (CE N $\left.N^{0} 00786 / C R E R S H C / 2019\right)$ and was administratively authorized by the Regional Delegate of Public Health for the Centre Region.(NO 00756-/AP/MINSANTE/SG/DRSPC/CRERSH). The study was performed in compliance with the World Medical Association Declaration of Helsinki on Ethical Principles for Medical Research Involving Human Subjects. A signed written informed consent form was obtained prior to the interview for those who agreed to participate.

\section{Consent for publication}

Not applicable.

\section{Competing interests}

The authors declare no competing interest in the study.

\section{Author details}

${ }^{1}$ Department of Public Health, Faculty of Medicine and Biomedical Sciences, University of Yaoundé 1, Yaoundé, Cameroon. ${ }^{2}$ Challenges Initiative Solutions, Yaoundé, Cameroon. ${ }^{3}$ Helen Keller International, Yaoundé, Cameroon. ${ }^{4}$ Department of Biochemistry, Faculty of Science, University of Yaoundé 1 , Yaoundé, Cameroon. ${ }^{5}$ Systems Biology, Chantal Biya International Reference Centre for Research on HIV and AIDS Prevention and Management (CBIRC), Yaoundé, Cameroon. ${ }^{6}$ UNICEF, Yaoundé, Cameroon. ${ }^{7}$ World Health Organisation, Yaoundé, Cameroon. ${ }^{8}$ Department of Disease Control, Epidemics and Pandemics, Ministry of Public Health, Yaoundé, Cameroon.

Received: 14 May 2020 Accepted: 30 November 2020 Published online: 17 December 2020

\section{References}

1. World Health Organisation. Monitoring the building blocks of health systems: A handbook of indicators and their measurement Strategies. 1st ed. Geneva: World Health Organization; 2011. ISBN-13: 978-9241564052. https://www.who.int/healthinfo/systems/WHO_MBHSS_2010_full_web. pdf

2. Hotchkiss DR, Diana ML, Foreit KG. How can routine health information systems improve health systems functioning in low- and middleincome countries? Assessing the evidence base. Adv Health Care Manag. 2012;12:25-58. https://doi.org/10.1108/s1474-8231.

3. Abayomi Joseph A, Timothy A, Adeola O, Abimbola O, Ganiyu A, Maduakolam $\mathrm{O}$. Factors that influence the use of routine health information in family planning services in Lagos, Nigeria. A prospective review of the use of family planning data. Res Rev Health Care Open Acc J. 2018;2(5). https://doi.org/10.32474/RRHOAJ.2018.02.000150.

4. Maïga A, Jiwani SS, Mutua MK, Porth TA, Taylor CM, Asiki G, et al. Generating statistics from health facility data: the state of routine health information systems in eastern and southern Africa. BMJ Glob Health. 2019;4(5):e001849. https://doi.org/10.1136/bmjgh-2019-001849.

5. Nicol E, Bradshaw D, Phillips T, Dudley L. Human factors affecting the quality of routinely collected data in South Africa. sStud Health Technol Inform. 2013;192:788-92.

6. Bennett A, Yukich J, Miller JM, Vounatsou P, Hamainza B, Ingwe MM, et al. A methodological framework for the improved use of routine health system data to evaluate national malaria control programs: evidence from Zambia. Popul Health Metrics. 2014;12(1):30. https://doi.org/10.1186/ s12963-014-0030-0.

7. Iyer HS, Kamanzi E, Mugunga JC, Finnegan K, Uwingabiye A, Shyaka E, et al. Improving district facility readiness: a 12-month evaluation of a data-driven health systems strengthening intervention in rural Rwanda. Glob Health Action. 2015;8:28365. https://doi.org/10.3402/gha.v8.28365.

8. Ahanhanzo YG, Saizonou J, Wodon A, Dujardin B, Wilmet-Dramaix M, Makoutodé M. Implication des agents de santé dans la conception des outils de collecte de données au Bénin [Health workers'involvement for data quality improvement in Benin]. Santé Publique. 2015;27(2):241-8. https://doi.org/10.3917/spub.152.0241.

9. Hanmer LA, Nicol E. Special people in routine health information systems implementation in South Africa. Stud Health Technol Inform. 2015;216:1000.

10. Teklegiorgis $K$, Tadesse $K$, Mirutse G, Terefe W. Level of data quality from health management information systems in a resources limited setting and its associated factors, eastern Ethiopia. South African Journal of Information Management. 2016;17(1):a612. https://doi.org/10.4102/sajim .v17i1.612.

11. Wandera SO, Kwagala B, Nankinga O, Ndugga P, Kabagenyi A, Adamou $B$, Kachero B. Facilitators, best practices and barriers to integrating family planning data in Uganda's health management information system. BMC Health Serv Res. 2019;19(1):327. https://doi.org/10.1186/s1291 3-019-4151-9. 
12. Ahanhanzo YG, Ouedraogo LT, Kpozèhouen A, Coppieters Y, Makoutodé M, Wilmet-Dramaix M. Factors associated with data quality in the routine health information system of Benin. Arch Public Health. 2014;72(1):25 https://doi.org/10.1186/2049-3258-72-25.

13. Endriyas M, Alano A, Mekonnen E, Ayele S, Kelaye T, Shiferaw M, et al. Understanding performance data: health management information system data accuracy in southern nations nationalities and People's region, Ethiopia. BMC Health Serv Res. 2019;19(1):175. https://doi.org/10.1186/ s12913-019-3991-7.

14. Kuyo R, Muiruri L. Organizational factors influencing the adoption of the district health information system 2 in Uasin Gishu County, Kenya. IJMRHS. 2018;7(10):48-57.

15. Ministry of Public Health (2019). National Digital Health Strategic Plan 2020 to 2024. https://www.minsante.cm/site/sites/default/files/ EN_DOCUMENT_PLAN\%20STRATEGIQUE\%20NATIONAL\%20DE\%20SAN TE\%20NUMERIQUE_R\%C3\%A9duit.pdf.

16. Ministry of Public Health. Health Sector Strategy 2016-2027. 2016. Yaounde. https://extranet.who.int/countryplanningcycles/sites/defau It/files/planning_cycle_repository/cameroon/cameroon_-_sss_valid ee_par_le_ccss_5_janvier.pdf.

17. Tamfon BB, Bilounga Ndongo C, Bataliack SM, Ngoufack MN, NguefackTsague G. Routine health information system in the health facilities in Yaoundé-Cameroon: assessing the gaps for strengthening. BMC Med Inform Decis Mak. 2020;20(1):316. https://doi.org/10.1186/s12911-02001351-3.

18. Centers for Disease Control and Prevention. Developing an effective evaluation plan: Setting the course for effective program evaluation. Atlanta; 2011.

19. Measure Evaluation. Routine health information system rapid assessment tool implementation guide. Chapel Hil: Measure Evaluation; 2018.

20. Indrayan A, Malhotra RK. Medical biostatistics. 4th ed: Chapman \& Hall/ CRC Press; 2017

21. Naing $L$, Winn T, Rusli BN. Practical issues in calculating the sample size for prevalence studies. Arch Orofac Sci. 2006;1:9-14.

22. Makinde OA, Onigbanjo-Williams A, Adeleke O, Ohadi EM, Awa DD, Osika JS. Assessment of the routine health management information system in Oyo state, Federal Republic of Nigeria. Bethesda: Health systems 20/20 project, Abt Associates Inc; 2012.

23. IBM-SPSS. IBM SPSS statistics for windows, Version 25, vol. 0. IBM Corp: Armonk; 2017.
24. Taber KS. The use of Cronbach's alpha when developing and reporting research instruments in science education. Res Sci Educ. 2018;48:127396. https://doi.org/10.1007/s11165-016-9602-2.

25. Tavakol M, Dennick R. Making sense of Cronbach's alpha. Int J Med Educ. 2011;2:53-5. https://doi.org/10.5116/ijme.4dfb.8dfd.

26. Shiferaw AM, Zegeye DT, Assefa S, Yenit MK. Routine health information system utilization and factors associated thereof among health workers at government health institutions in east Gojjam zone, Northwest Ethiopia. BMC Med Inform Decis Mak. 2017;17(1):116. https://doi.org/10.1186/ s12911-017-0509-2.

27. Asemahagn MA. Determinants of routine health information utilization at primary healthcare facilities in Western Amhara, Ethiopia. Cogent Med. 2017:4(1). https://doi.org/10.1080/2331205X.2017.1387971.

28. Belay $\mathrm{H}, \mathrm{Azim} \mathrm{T}$, Kassahun $\mathrm{H}$. Assessment of health management information system ( HMIS ) performance in SNNPR. Ethipia: USAID Measure Evaluation; 2014. https://www.measureevaluation.org/resources/publi cations/sr-14-87.

29. Cheburet SK, Odhiambo-Otieno GW. Process factors influencing data quality of routine health management information system: case of Uasin Gishu County referral hospital, Kenya. Int J Environ Res Public Health. 2016;3(6):132-9. https://doi.org/10.15739/irjpeh.16.017.

30. Karuri J, Waiganjo P, Orwa D, Manya A. (2014). DHIS2: the tool to improve health data demand and use in Kenya. J Health Inform Dev Ctries. 2014;8(1):38-60.

31. Kiberu VM, Matovu JK, Makumbi F, Kyozira C, Mukooyo E, Wanyenze RK. Strengthening district-based health reporting through the district health management information software system: the Ugandan experience. BMC Med Inform Decis Mak. 2014;14:40. https://doi. org/10.1186/1472-6947-14-40.

32. Ministry of Public Health (2016). Cameroon National Health Development Plan 2016-2020. https://extranet.who.int/countryplanningcycles/sites/ default/files/planning_cycle_repository/cameroon/cameroon_-_draft _pnds_02.08.16.docx.

\section{Publisher's Note}

Springer Nature remains neutral with regard to jurisdictional claims in published maps and institutional affiliations.
Ready to submit your research? Choose BMC and benefit from:

- fast, convenient online submission

- thorough peer review by experienced researchers in your field

- rapid publication on acceptance

- support for research data, including large and complex data types

- gold Open Access which fosters wider collaboration and increased citations

- maximum visibility for your research: over $100 \mathrm{M}$ website views per year

At BMC, research is always in progress.

Learn more biomedcentral.com/submissions 